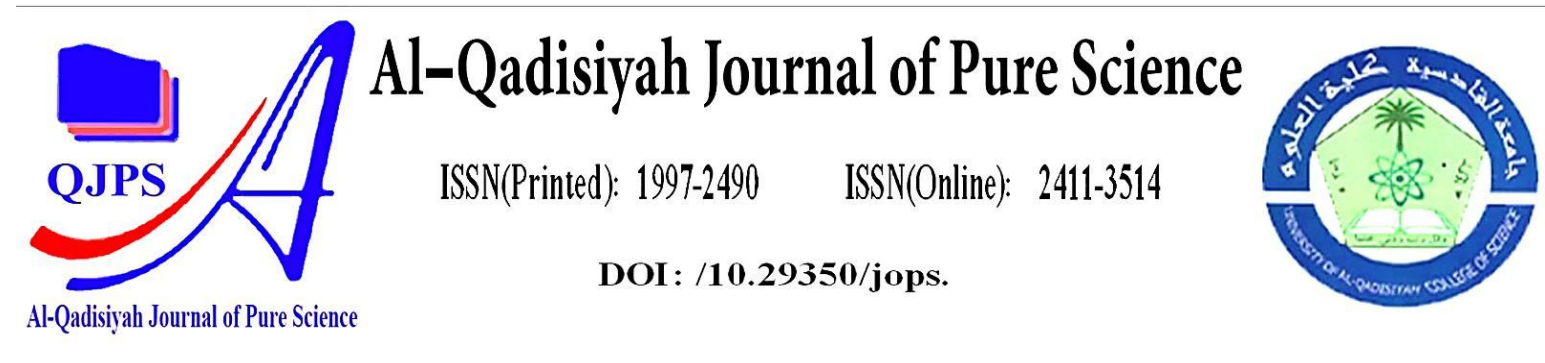

\title{
Modified Hermite Operational Matrix Method for Nonlinear Lane-Emden Problem
}

Authors Names
Bushra Esaa Kashem
Article History
Received on: $2 / 5 / 2020$
Revised on: $8 / 6 / 2020$
Accepted on: 24/6/2020
Keywords:
Collocation method
Nonlinear Lane-Emden equation
modified Hermite function
integration operational matrix
initial value problem.

Authors Names

Bushra Esaa Kashem

Article History

Received on: $2 / 5 / 2020$

Revised on: $8 / 6 / 2020$

Keywords:

Collocation method modified Hermite function

initial value problem.

\begin{abstract}
Nonlinear Lane-Emden equations are significant in astrophysics and mathematical physics. The aim of this paper is introducing a new approximate method for finding solution to nonlinear Lane-Emden type equations appearing in astrophysics based on modified Hermite integration operational matrix. The suggested technique is based on taking the truncated modified Hermite series of the solution function in the nonlinear Lane-Emden equation and then changed into a matrix equation with the given conditions. Nonlinear system of algebraic equation using collection points is obtained. The present method is applied on some relevant physical problems as nonlinear Lane-Emden type equations.
\end{abstract}

\section{MSC: $30 C 45,30 C 50$}

DOI: https://doi.org/10.29350/

jops.2020.25. 3.1128

\section{Introduction:}

Nonlinear Lane-Emden equations are initial value problems with singularity at the origin. They have the interest of many physics and mathematician because of their importance in many fields such as a mathematical physics and astrophysics [7, 8, 11, 19,1]. Nonlinear Lane-Emden problem has been studied by many researchers and solved using different method. For example, in [10] nonlinear Lane-Emden solved by hybrid Bernstien wavelete method, while the authors [12], Chebyshev orthogonal function are used and [2] applied variation iteration method to approximate solution. Some other approximate solutions are used such as Tau method [16]. To more studies, related to Lane-Emden type equations we can see $[17,13,18]$. The collocation method has been a very important and useful technique to find the approximate solution of Lane-Emden equation method based on third degree B-Spline suggest in [14], In $[15,9]$, collocation method was applied to solve system of Lane-Emden equation depending on Chebyshev polynomials. Moreover, orthogonal polynomial and wavelets establish a relation with fast approximate techniques and they are successfully used in many fields such as boundary value problem and optimal control problem [3-6].

\footnotetext{
${ }^{a}$ Applied Sciences Department , University of Technology, Baghdad, Iraq, E-Mail: bushra eesa@ yahoo.com
} 
The essential important of this work is considering modified Hermite polynomials with integration operational matrix for solving nonlinear singular Lane-Emden equation.

The fulfillment of the suggested method reduces the original problem to a system of nonlinear equations, which can easily be solved with computer.

2. Modified Hermite Polynomials:

For $\mathrm{a} \geq 0$, the definition of modified Hermite polynomial $\mathrm{H}_{\mathrm{m}}^{\mathrm{a}}(\mathrm{x})$ is

$$
\sum_{\mathrm{m}=0}^{\infty} \frac{\mathrm{H}_{\mathrm{m}}^{\mathrm{a}}}{\mathrm{m} !}=\mathrm{a}^{2 \mathrm{xt}-\mathrm{t}^{2}}, \quad|\mathrm{t}|<\infty
$$

by Maclurin series, extend the right hand of eq.(1) in x and modify coefficients,

$\mathrm{H}_{\mathrm{m}}^{\mathrm{a}}(\mathrm{x})=\mathrm{m} ! \sum_{\mathrm{k}=0}^{\lfloor\mathrm{m} / 2\rfloor} \frac{-1^{\mathrm{k}}(2 \mathrm{x})^{\mathrm{m}-2 \mathrm{k}}(\operatorname{loga})^{\mathrm{m}-\mathrm{k}}}{(\mathrm{m}-2 \mathrm{k}) ! \mathrm{k} !}$

for $\mathrm{a}=2$,one can get :-

$\mathrm{H}_{0}^{2}(\mathrm{x})=1, \mathrm{H}_{1}^{2}(\mathrm{x})=2 \mathrm{Gx}, \mathrm{H}_{2}^{2}(\mathrm{x})=4 \mathrm{G}^{2} \mathrm{x}^{2}-2 \mathrm{G}, \mathrm{H}_{3}^{2}(\mathrm{x})=8 \mathrm{G}^{3} \mathrm{x}^{3}-12 \mathrm{G}^{2} \mathrm{x}$

$H_{4}^{2}(x)=16 G^{4} x^{4}-48 G^{3} x^{2}+12 G^{2}, H_{5}^{2}(x)=32 G^{5} x^{5}-160 G^{4} x^{3}+120 G^{3} x+12 G^{2}$

where $\mathrm{G}=\log 2$

3. Properties of Modified Hermite Polynomial:

The following properties are familiar for modified Hermite polynomial.

The recurrence relation to modified Hermite polynomial

$\mathrm{H}_{\mathrm{m}+1}^{2}(\mathrm{x})=\mathrm{G}\left(2 \mathrm{x} \mathrm{H}_{\mathrm{m}}^{2}(\mathrm{x})-2 \mathrm{mH}_{\mathrm{m}-1}^{2}(\mathrm{x})\right)$

with $\mathrm{H}_{0}^{2}(\mathrm{x})=1, \mathrm{H}_{1}^{2}(\mathrm{x})=2 \mathrm{Gx}, \mathrm{m}=1,2, \ldots$

The derivative of modified Hermite polynomial can be obtained from eq.(2)

$\dot{\mathrm{H}}_{\mathrm{m}}^{2}(\mathrm{x})=2 \mathrm{~m} \mathrm{GH}_{\mathrm{m}-1}^{2}(\mathrm{x})$

by eq.(3)and (4), one can obtain

$\ddot{\mathrm{H}}_{\mathrm{m}}^{2}(\mathrm{x})=2 \mathrm{xG} \dot{\mathrm{H}}_{2}^{\mathrm{a}}(\mathrm{x})+2 \mathrm{mGH}_{\mathrm{m}}^{2}(\mathrm{x})$

and by measure function $\mathrm{w}(\mathrm{x})=2^{-\mathrm{x}^{2}}$ can be estimate the orthogonal for polynomial $\mathrm{H}_{\mathrm{m}}^{2}(\mathrm{x})$

$$
\int_{-\infty}^{\infty} H_{m}^{2}(x) H_{n}^{2}(x) 2^{-x^{2}} d x= \begin{cases}2^{m} m ! G^{m^{2}}(\pi / G)^{1 / 2} & m=n \\ 0 & m \neq n\end{cases}
$$

4. Integration Operational Matrix for Modified Hermite Polynomials:

The explicated to integration of vector $\mathrm{H}_{\mathrm{m}}^{2}(\mathrm{x})$ is

$\int_{0}^{\mathrm{x}} \mathrm{H}_{\mathrm{m}}^{2}(\mathrm{x}) \mathrm{dx}=\mathrm{A}_{\mathrm{H}} \mathrm{H}_{\mathrm{m}}^{2}(\mathrm{x})$

$A_{H}$ is $(m+1) \times(m+1)$ integration operational matrix for modified Hermite polynomial. 
$\mathrm{H}_{\mathrm{m}}^{2}(\mathrm{x})$ of order $\mathrm{m}$ can be expressed as follows

$$
\begin{aligned}
& \int_{0}^{\mathrm{x}} \mathrm{H}_{\mathrm{m}}^{2}(\mathrm{x}) \mathrm{dx}=\frac{1}{2 \mathrm{G}(\mathrm{m}+1)}\left\{\mathrm{H}_{\mathrm{m}+1}^{2}(\mathrm{x})-\mathrm{H}_{\mathrm{m}+1}^{2}(0) \mathrm{H}_{0}^{2}\right. \\
& \text { with } \mathrm{H}_{\mathrm{m}+1}^{2}(0)= \begin{cases}(-1)^{\frac{\mathrm{m}+1}{2}} \mathrm{G}^{\frac{\mathrm{m}+1}{2}} \frac{(\mathrm{m}+1) !}{\left(\frac{\mathrm{m}+1}{2}\right) !} & \text { m odd } \\
0 & \text { m even }\end{cases}
\end{aligned}
$$

$\mathrm{A}_{\mathrm{H}}$ matrix can be formed as:

$$
\mathrm{A}_{\mathrm{H}}=\left[\begin{array}{cccccc}
0 & \frac{1}{2 G} & \ldots & 0 & 0 & 0 \\
-2 G & 0 & \frac{1}{4 G} & \ldots & 0 & 0 \\
\vdots & \vdots & \vdots & \vdots & \vdots & \vdots \\
(-1)^{\frac{m+1}{2}} \frac{(m+1) !}{\left(\frac{m+1}{2}\right) !} & \vdots & \vdots & \vdots & \vdots & \frac{1}{2 G(m+1)}
\end{array}\right]
$$

for even $m$ the last row will be

$$
\left[\begin{array}{lllllll}
0 & \frac{1}{2 \mathrm{G}} & 0 & \frac{1}{4 \mathrm{G}} & 0 & \ldots & \frac{1}{2 \mathrm{G}(\mathrm{m}+1)}
\end{array}\right]
$$

\section{Methodology of Solution by Integration Operational Matrix:}

In this section, the integration operational matrix is used with collocation method to solve nonlinear Lane-Emden equation.

assume the nonlinear Lane-Emden equation

$\ddot{z}+\frac{\alpha}{x} \dot{z}+f(x, z)=g(x)$

$\mathrm{z}(0)=\gamma \quad$ and $\quad \dot{\mathrm{z}}(0)=\beta$

where $f(x, z)$ is a nonlinear function.

by extending $\ddot{z}$ in modified Hermite polynomials, one can get

$\ddot{\mathrm{z}}(\mathrm{x})=\mathrm{C}^{\mathrm{T}} \mathrm{H}^{2}(\mathrm{x})$

where $\mathrm{c}=\left[\begin{array}{llll}\mathrm{c}_{0} & \mathrm{c}_{1} & \ldots & \mathrm{c}_{\mathrm{m}}\end{array}\right]^{\mathrm{T}}$

$\mathrm{H}^{2}(\mathrm{x})=\left[\begin{array}{llll}\mathrm{H}_{0}^{2} & \mathrm{H}_{1}^{2} & \ldots & \mathrm{H}_{\mathrm{m}}^{2}\end{array}\right]^{\mathrm{T}}$

Integrate eq.(12) twice from 0 to $\mathrm{x}$ with respect $\mathrm{x}$ and conditions given in eq.(11), we obtain

$\dot{\mathrm{z}}(\mathrm{x})=\mathrm{C}^{\mathrm{T}} \mathrm{A}_{\mathrm{H}} \mathrm{H}^{2}(\mathrm{x})+\beta$

$\mathrm{z}(\mathrm{x})=\mathrm{C}^{\mathrm{T}} \mathrm{A}_{\mathrm{H}}^{2} \mathrm{H}^{2}(\mathrm{x})+\beta+\gamma$

eq.(14) declares the expression of the solution in eq.(10).

By substituting eq.(12),(13), and(14) into eq.(10) and using discretization collocation points, a nonlinear system equations is obtained with unknown coefficients $c_{0}, c_{1}, \ldots, c_{m}$. That will be solved by new ton iteration method using matlab. 
6. Numerical Example:

In this section, we expound the activity of the proposed method with three nonlinear Lan e-Emden equations.

Example 1:

Consider the nonlinear Lane-Emden equation

$\ddot{y}(x)+\frac{2}{x} \dot{y}(x)+4\left(2 e^{y}+e^{\frac{y}{2}}\right)=0$

with conditions $y(0)=\dot{y}(0)=0$

exact solution $\mathrm{y}(\mathrm{x})=-2 \ln \left(1+\mathrm{x}^{2}\right)$

we assume $\ddot{y}=\sum_{n=0}^{5} C_{n} H_{n}(x, a), \quad a=2$

by applying the proposed method and integrate the eq.(15) twice with respect to $\mathrm{x}$ from 0 to $\mathrm{x}$ and Substituting the initial conditions, we obtainy $, \dot{y}, y$, then by Substituting them in eq.(15) and using collocation points we get system with 6 unknown's coefficients. After solving this system by newton iteration method and substituted the coefficients we find the approximate solution. Table 1 and fig. 1 clarify the comparison between the exact and approximate solution by hermite[12], modified Hermite with absolute error.

Example 2:

Consider the Lane-Emden equation

$$
\ddot{y}+\frac{2}{x} \dot{y}+\sin (y(x))=0, \quad x>0
$$

$\mathrm{y}(0)=1, \dot{\mathrm{y}}(0)=0$

Here we assume $\ddot{y}=\sum_{n=0}^{8} C_{n} H_{n}(x, a), \quad a=2$

By applying the same method and solving the nonlinear system by newton iteration we approximate solution for the equation. Table 2 and fig. 2 clarify the comparison of solution and absolute error with Wazwaz[20] and Pranda[12].

Example 3:

The nonlinear Lane-Emden equation

$\ddot{y}+\frac{1}{x} \dot{y}-y^{3}+3 y^{5}=0$

Subject to the initial condition $\mathrm{y}(0)=1, \dot{\mathrm{y}}(0)=0$, and exact solution $\mathrm{y}=\left(1+\mathrm{x}^{2}\right)^{\frac{-1}{2}}$

Here we assume $\ddot{y}=\sum_{n=0}^{6} C_{n} H_{n}(x, a), \quad a=2$

Table 3 and fig. 3 reflects the comparison between the approximate solution with exact solution and absolute error. 


\section{Conclusion:}

In this work nonlinear Lane-Emden problems have been solved by using modified Hermite integration operational matrix. The approached plan is tested by some examples and the results are satisfied in comparison with approximate with existing.

References:

1. Abdel-Salam, E., \& Nouh, M., "Conformable fractional polytrophic gas spheres", New Astronomy, 2020, 76, 101322 .

2. Asghar G., Mojtaba B., "Avariational iteration method for solving nonlinear Lane-Emden problems. New Astronomy, 2017, 54,1-6.

3. Alrawy, S. \& Salih, A., "Shifted modified chebyshev direct method for solving quadratic optimal control problem", Samarra Journal of Pure and Applied Science, 2020, 2(1), 67-75.

4. Bushra E., "Hermite Wavelet Approach to Estimate Solution for Bratu’S Problem", Emirates Journal for Engineering Research, 2019, 24(2).

5. Bushra E., Hayat A. \& Israa H., "A New Modified Laguerre Collocation Method for Solving ThreePoint Boundary Value Problems", Journal of College of Education, 2016, 3(3), 141-148.

6. Delphi, M., Shihab, S., "Operational Matrix Basic Spline Wavelets of Derivative for linear Optimal Control Problem", Electronics Science Technology and Application, 2019, 6(2), 18-24.

7. Galise G.,"On Positive Solution of Fully Nonlinear Degenerate Lane-Emden type Equation" Journal of Differential Equations, 2019, 266(2-3), 1675-1697.

8. Iqbal M.,Abbas M. \& Wasim I., "New Cubic B-spline Approximation for Solving Third Order EmdenFlower Type Equations", Applied Mathematics and Computation,2018,331,319-333.

9. Jafari R., Ezzati R. \& Maleknejad K., " Numerical Solution of Lane-Emden Type Equation by Using Hybrid Third Kind Chebyshev Polynomials and Block-Pulse Functions Operational Matrix of Differentiation", Journal of Mathematical Extension, 2018 , 12(2), 15-32.

10. Mohamed R., Mehdi D.," Anew Algorithm for Solving the Nonlinear Lane-Emden Equations arising in Astrophysics", SN Applied Sciences, 2019,183.

11. Ozturky Y., Gulsu M., "An Approximation Algorithm for the solution of the Lane-Emden Type Equation Arising in Astrophysics and Engineering Using Hermite Polynomials", Comp. Appl.Math., 2014, 33(1), 131-145.

12. Parand K., Mehdi D., "An Effective Numerical Method for Solving the Nonlinear Singular LaneEmden Type Equations of Various order",Jurnal Tecknology ,2017,79:1,25-36.

13. Parand K., Yousefi H. \& Delkhosh M.," A numerical approach to solve Lane-Emden type equations by the fractional order of rational Bernoulli functions", Romanian J. Phys, 2017, 62(104), 1-24.

14. Parsaeitabar Z., Nazem A.," A Third-degree B-spline Collocation Scheme for Solving a Class of the Nonlinear Lane--Emden Type Equations", Iranian Journal of Mathematical Sciences and Informatics, 2017, 12(2), 15-34.

15. Singh R., Garg H. \& Guleria V., "Haar wavelet collocation method for Lane-Emden equations with Dirichlet, Neumann and Neumann-Robin boundary conditions. Journal of Computational and Applied Mathematics, 2019, 346,150-161.

16. Tohidi E., Erfani Kh.\& Shateyi S.," Anew Tau Method for solving Nonlinear Lane-Emden Type Equations via Bernoulli Operational Matrix of Differentiation", Journal of Applied Mathematics, 2013,9 . 
17. Ullah A., Shah K.," Numerical analysis of Lane Emden-Fowler equations", Journal of Taibah University for Science, 2018, 12(2), 180-185.

18. Vanani S., Aminataei A.," On the numerical solution of differential equations of Lane-Emden type", Computers \& Mathematics with Applications, 2010, 29(8), 2815-2820.

19. Wazwaz A., "Solving the Non-isothermal reaction Diffusion Model Equations in a Spherical Catalyst by the Variational Iteration Method", Chemical Physics Letters, 2017, 679, 132-136.

20. Wazwaz A., "Anew Algorithm for Solving Differential Equations of Lane-Emden Type", Applied Mathematics and Computation, 2001, 118(2), 287-310. 
Table 1

\begin{tabular}{|c|c|c|c|c|c|}
\hline $\mathrm{x}$ & Exact & Parand[12],N=30 & $\begin{array}{c}\text { Absolute } \\
\text { error }\end{array}$ & Present Method, $\mathrm{N}=5$ & $\begin{array}{c}\text { Absolute } \\
\text { error }\end{array}$ \\
\hline 0 & 0 & 0 & 0 & 0 & 0 \\
\hline 0.01 & 0.000199 & 0.000197 & 0.000002 & 0.000196 & 0.000003 \\
\hline 0.1 & 0.019900 & 0.019897 & 0.000003 & 0.019901 & 0.000001 \\
\hline 0.5 & $-\quad 0.446287$ & $-\quad 0.446284$ & 0.000003 & 0.446286 & 0.000001 \\
\hline 1.0 & 1.386294 & $-\quad 1.386293$ & 0.000001 & 1.386292 & 0.000002 \\
\hline 2.0 & $-\quad 3.218875$ & $-\quad 3.218876$ & 0.000001 & $-\quad 3.218876$ & 0.000001 \\
\hline 3.0 & 4.605170 & 4.605171 & 0.000001 & 4.605171 & 0.000001 \\
\hline 4.0 & 5.666426 & $-\quad 5.666427$ & 0.000001 & $-\quad 5.666426$ & 0.000000 \\
\hline 5.0 & 6.516193 & 6.516194 & 0.000001 & 6.516192 & 0.000001 \\
\hline 6.0 & 7.221835 & 7.221836 & 0.000001 & 7.221835 & 0.000000 \\
\hline
\end{tabular}

Table 2

\begin{tabular}{|c|c|c|c|c|c|}
\hline $\mathrm{x}$ & Wazwaz[20] & Parand[12],N=15 & Absolute error & Present Method,N=8 & Absolute error \\
\hline 0 & 1.0000000 & 1.000000 & 0 & 1.000000 & 0 \\
\hline 0.1 & 0.998598 & 0.998605 & 0.000007 & 0.998588 & 0.00001 \\
\hline 0.2 & 0.994396 & 0.994406 & 0.00001 & 0.994395 & 0.000001 \\
\hline 0.5 & 0.965178 & 0.965188 & 0.00001 & 0.965177 & 0.000001 \\
\hline 1.0 & 0.863681 & 0.863688 & 0.000007 & 0.863679 & 0.000002 \\
\hline 1.5 & 0.705042 & 0.705052 & 0.00001 & 0.705044 & 0.000002 \\
\hline 2.0 & 0.506372 & 0.506469 & 0.000097 & 0.506383 & 0.000011 \\
\hline
\end{tabular}

Table 3

\begin{tabular}{|c|c|c|c|}
\hline $\mathrm{x}$ & Present Method & Exact & Absolute error \\
\hline 0 & 1 & 1 & 0 \\
\hline 0.1 & 0.995036 & 0.995037 & 0.000001 \\
\hline 0.2 & 0.980582 & 0.980581 & 0.000001 \\
\hline 0.3 & 0.957827 & 0.957826 & 0.000001 \\
\hline 0.4 & 0.928477 & 0.928477 & 0.000000 \\
\hline 0.5 & 0.894439 & 0.894427 & 0.000012 \\
\hline 0.6 & 0.857493 & 0.857493 & 0.000000 \\
\hline 0.7 & 0.819231 & 0.819232 & 0.000001 \\
\hline 0.8 & 0.780868 & 0.780869 & 0.000001 \\
\hline 0.9 & 0.743293 & 0.743294 & 0.000001 \\
\hline 1 & 0.707106 & 0.707107 & 0.000001 \\
\hline
\end{tabular}




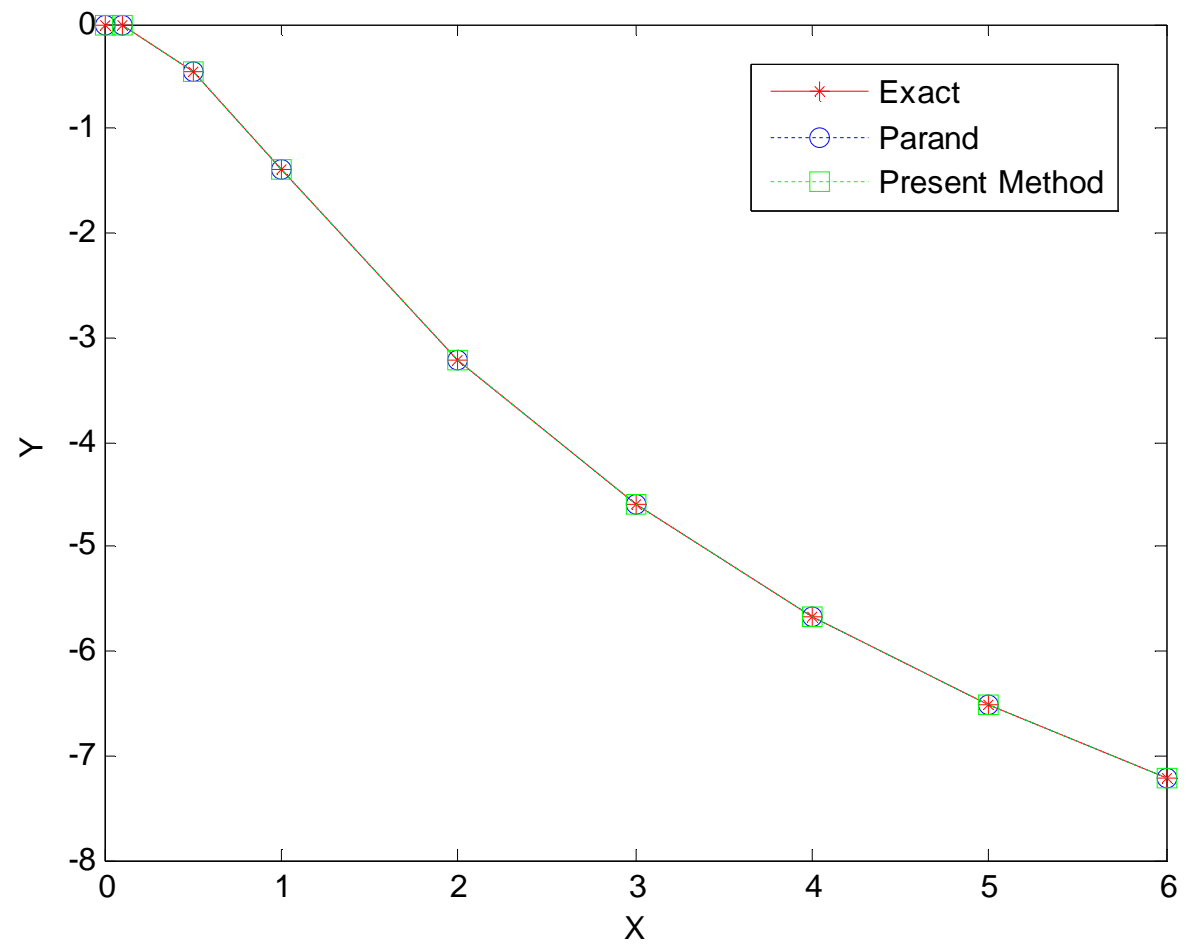

Fig.1

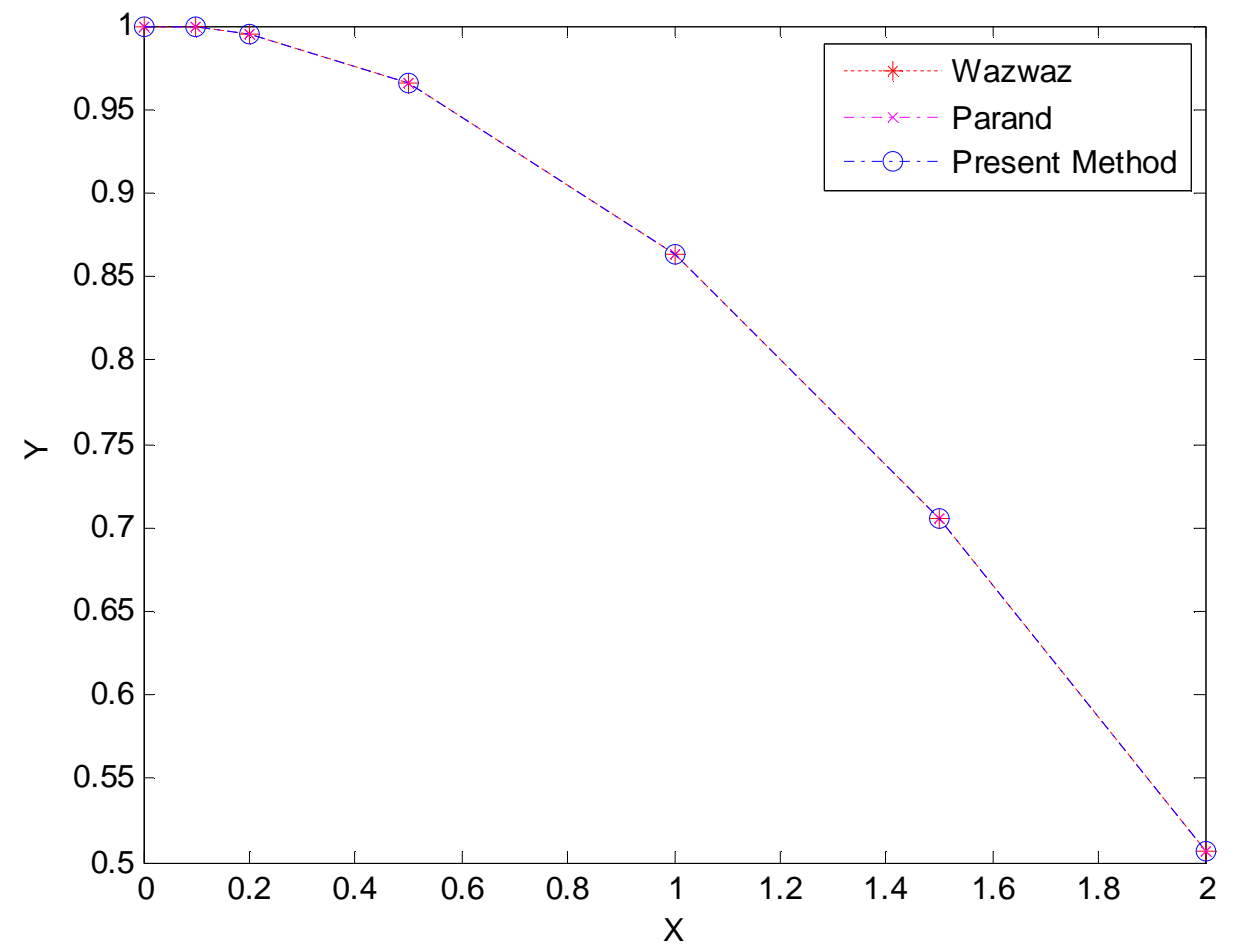

Fig.2 


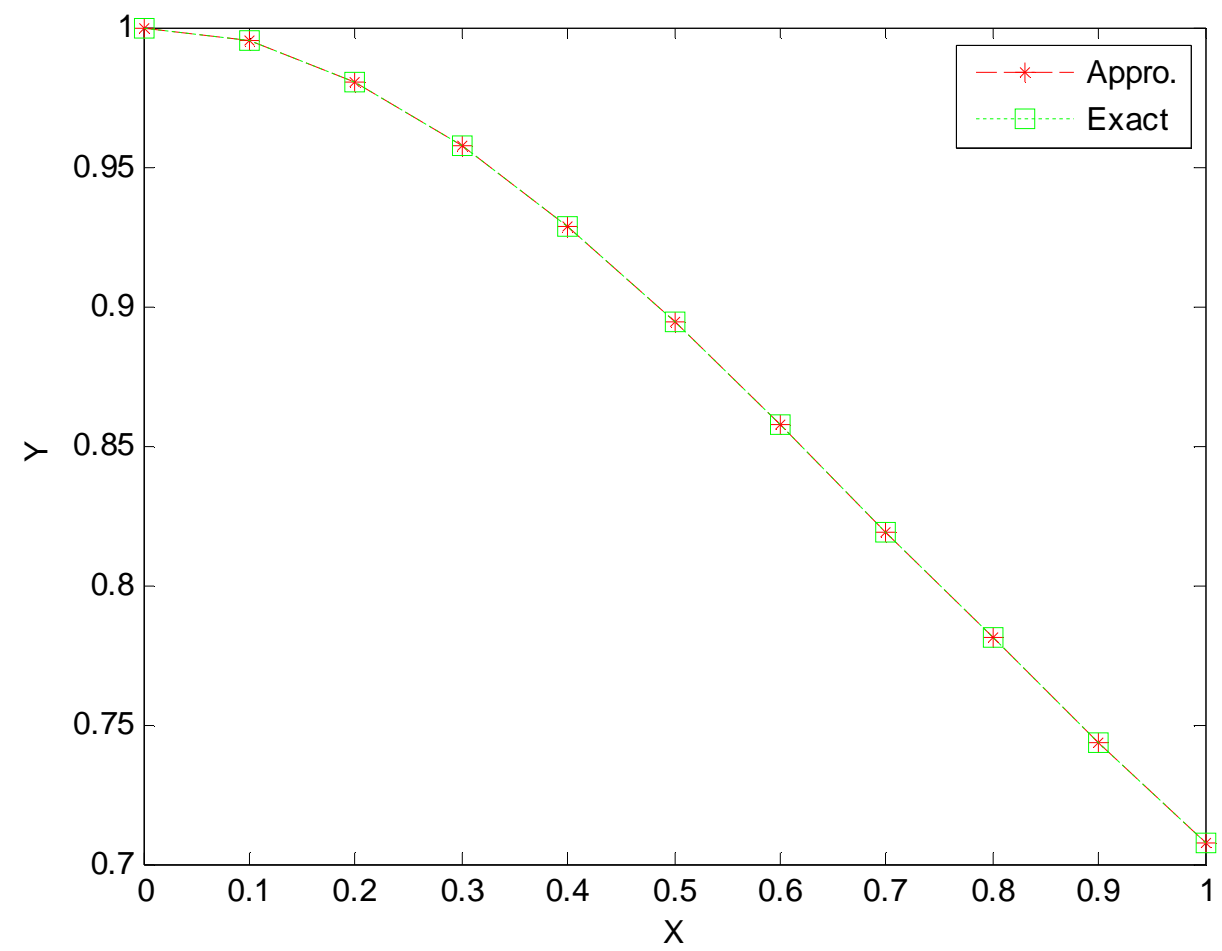

Fig.3 